\title{
A AÇÃO EDUCATIVA DOS PROFESSORES DE EDUCAÇÃO FÍSICA: TEORIA E PRÁTICA
}

\author{
LeNIR Miguel DE LiMA*
}

RESUMO

O presente texto apresenta as diferentes concepções de prática educativa e sua evolução histórica, buscando em diversos autores os subsídios para clarificar o distanciamento entre Teoria e Prática e seus reflexos socio-culturais. Pretende, ainda, relacionar a prática educativa, a teoria e o currículo com os valores e fins da Educação Física Escolar.

PALAVRAS-CHAVE: Teoria - Prática Educativa - Currículo - Ideologia - Educação Física.

\section{A EDUCAÇÃO COMO FENÔMENO EDUCATIVO}

\section{A construção da prática educativa}

S vários significados da educação trilharam um longo caminho através da história da humanidade. Aos estudiosos da educação interessa a discussão e a reflexão epistemológica desta, bem como do que a provocou, principalmente as causas relacionadas ao social, ao cultural e ao econômico.

A busca constante entre utopia e realidade é uma característica do ser humano e a construção do conhecimento tem se configurado pelo "fazer" cotidiano de épocas distintas, mesmo que esse às vezes seja desconsiderado pela "formalização culta" do pensamento (Sacristán, p. 1988).

A evolução histórica da teoria da educação sofreu várias mudanças, principalmente nos anos 70 , quando a perspectiva ortodoxa foi muito criticada pelos filósofos. Estes a atacavam por suas suposições de caráter "confuso", "vago" e "pseudoteórico" (Carr,

* Professora da Faculdade de Educação Física da Universidade Federal de Goiás, doutoranda em Filosofia e Ciências da Educação na Universidade de Valência - Espanha; sóciapesquisadora do Colégio Brasileiro de Ciências do Esporte (CBCE). 
1996, p. 52). Com tais ataques, as mudanças se centraram em algumas modificações, não muito relevantes, como a eliminação daquelas características e a busca de respaldo em disciplinas acadêmicas, como filosofia, psicologia e sociologia, que, segundo acreditava-se, seriam fundamentais para a teoria da educação. Também ocorreram modificações na reorganização dos departamentos e na reestruturação das disciplinas, sustentadas por novas revistas e sociedades acadêmicas que os defendiam. Todavia, em meados dos anos 70 , chegaram à conclusão de que os problemas educativos não estavam contidos nos estreitos limites de nenhuma disciplina isolada e, portanto, faziam-se necessárias novas reformulações com respeito à relevância da teoria da educação. Assim,

como conseqüência destas dúvidas internas, se aceitou, no plano ritual, o caráter 'interdisciplinário', 'integrado' e 'baseado' nos problemas da teoria da educação, começando a buscar-se, então, formas de superar as distâncias entre a teoria da educação e as práticas que dão a toda essa teoria sua razão de ser. (Carr, 1996, p. 53)

Num certo momento, a teoria da educação foi considerada como um conjunto de princípios práticos originados de filosofias gerais ou baseados nas convicções dos "grandes educadores", como Platão, Rousseau, Hebart, Froebel e Pestalozzi.

Sem dúvida, a maior dificuldade para compreender essa concepção de teoria da educação estava no distanciamento entre os princípios abstratos por ela gerados e a realidade enfrentada pelos professores nas aulas. Todavia, este não foi o principal motivo da eliminação deste enfoque, mas sim as críticas da filosofia analítica sobre suas suposições metodológicas básicas. Apesar de possuir distintas concepções, a teoria da educação aceita algumas suposições básicas acerca da teoria e da prática educativa, as quais não têm sido discutidas seriamente. Seu objetivo principal é mantido como a formulação de princípios gerais que os professores podem usar para solucionar seus problemas nas aulas e, conseqüentemente, melhorar a prática educativa. Portanto, a mera aplicação de métodos e/ou de critérios de outras teorias não podem assegurar a resolução dos problemas e a melhora da prática educativa. Apenas a 
sistematização e a rigorosidade em explorar o conjunto concreto de dificuldades pode fazê-lo.

Uma questão que fica pendente é: "Deve a educação depender intrinsecamente das disciplinas acadêmicas?"

Nas afirmações de Carr (1996) encontramos alguns conceitos de educação que poderão aclarar melhor esta questão. O autor afirma que a educação não é uma atividade teórica, senão uma atividade prática, pois tem "o objetivo geral de desenvolver as mentes dos alunos mediante os processos de ensino e aprendizagem" ( $p$. 56). Defende, também, que qualquer pessoa que se ocupe de tarefas educativas possui uma teoria, mesmo que não tenha consciência dela.

Apesar das numerosas conotações do termo "teoria", suas definições estão inseridas em um destes pontos: o científico (onde as hipóteses são conectadas e verificadas), ou o genérico, quando só se consideram os objetos e as informações de modos vagos e gerais. Assim, o termo possui dois significados diferentes: ser um produto concreto da investigação, que se utiliza de princípios, leis e explicações, ou "o marco do pensamento que estrutura e guia qualquer atividade teórica característica" (Carr, 1996, p. 55).

Não obstante, as práticas educativas terem alguma aproximação conceitual com as práticas psicológicas, como nos conceitos de aprendizagem, inteligência e interesse, ambas possuem interpretações distintas dos mesmos.

Os distanciamentos criados entre teoria e prática são produtos da comunicação entre os teóricos e os práticos, devido à diferença entre a linguagem da teoria da educação e a da prática educativa. Portanto, é necessário que a teoria da educação descubra formas de aproximação com os professores para induzi-los a aceitar e aplicar a teoria que se lhes oferece. Isto somente se tornará um fato quando a teoria da educação incluir o marco teórico que dá sentido a estas práticas.

A teoria da educação não é uma teoria aplicada - baseada em outras, como filosofia, sociologia etc. -, portanto, o medo de prescindir destas disciplinas acadêmicas não a privará de sua validez, legitimidade e verdade. 
Segundo Carr (1996, p. 61),

a teoria da educação consiste em desenvolver teorias da prática educativa intrinsecamente relacionadas com as próprias explicações que os profissionais dão do que estão fazendo, que melhorem a qualidade de sua participação nessas práticas, e, portanto, permitindo-lhes exercê-las melhor.

A relação de reciprocidade entre a teoria da educação e a prática educativa deve ser vista com seriedade, para que aquela, ao transformar-se, faça a transformação desta. Portanto, a característica básica da teoria da educação deve ser a emancipação dos professores de sua dependência das práticas, desenvolvendo formas de análise e de investigação para expor e examinar as crenças e os valores básicos no marco teórico.

"Na educação, a teoria é uma dimensão indispensável da prática" (Carr, 1996, p. 62).

\section{A ação educativa e a prática social}

No senso comum, o distanciamento entre a teoria e a prática é analisado como originário das ações e ocupações das pessoas em seus labores; ou seja, os teóricos fazem a teoria e os práticos, a prática em seus contextos laborais. Assim, na educação, a teoria seria aquela produzida na universidade, nas agências de pesquisa ou nos centros de formação de professores. Já a prática da educação estaria sendo desenvolvida nos centros escolares não-universitários, pelos professores ali estabelecidos.

Nesta visão há uma limitação entre o conhecimento e a ação educativa, intensificada pela divisão social do trabalho, pela interrelação e mesmo pela confrontação entre as instituições educativas, as agências de pesquisas e os profissionais da educação.

Outra análise limitada que costuma ocorrer é a redução das relações e desencontros entre dois tipos de agentes, os teóricos e os práticos, no contexto restrito às suas ações laborais. Ou seja, no sistema educativo deve-se considerar um contexto mais amplo, com outros setores e agentes sociais, que, à margem das decisões, "transportam idéias à prática”. Portanto, como bem define Sacristán (1998, 
p. 23), todo aquele indivíduo ou grupo que decide sobre a educação (que é portador de teorias) e sobre as razões que leva consigo quando o faz, é agente da prática.

Assim terão poder de decisão sobre a educação os parlamentares, os sindicatos e associações de professores, os pais, os alunos e tantos quantos houverem nesta divisão de responsabilidade educativa e social. Neste panorama, Sacristán (1998) considera, como terceira suposição sobre a relação entre teoria e prática, aquela que considera o trabalho dos teóricos e práticos como uma forma de acercamento entre a teoria e a prática. Não obstante, em sua análise, aponta os erros desta visão, porque esta aproximação não garante a fecundação mútua e nem soluciona o desencontro entre teoria e prática. Isto seria o mesmo que dizer, no senso comum, que os professores fazem a prática e os filósofos, pesquisadores e pensadores, a teoria. Essa polaridade dificulta seu acercamento, implicando o difícil acesso ao mundo da reflexão e constituindose, portanto, em uma visão errônea, pois nenhum dos dois são donos ou criadores da prática ou da teoria, respectivamente (Sacristán, 1998, p. 25).

O reflexo antiteórico é resultado do distanciamento e da incompreensão da linguagem pelos professores, um mecanismo de defesa que criaram, por considerar a teoria uma inutilidade para a prática. Portanto, uma solução para esse distanciamento seria a aproximação das linguagens, a seleção de temas adequados e o trabalho compartido, com propostas de pesquisa a serviço e de acordo com as necessidades da prática (Sacristán, 1998).

Assim, é necessário um entendimento mais amplo e profundo sobre os conceitos da prática, suas relações com o saber e o poder, sua ação individual e social, pois, segundo Sacristán (1998, p. 33),

a prática se entende como a atividade dirigida aos fins conscientes, como ação transformadora de uma realidade; como atividade social, historicamente condicionada, dirigida à transformação do mundo; como a razão que fundamenta nossos saberes, o critério para estabelecer sua verdade; como a fonte de conhecimentos verdadeiros; o motivo dos processos de justificação do conhecimento. 
Neste mesmo sentido Kemmis, citado por Carr (1996), fala da prática como algo que deve ser pensado e construído, não como uma mera atividade, pois a prática educativa existe nos planos social, histórico e político. Como tal, não deve ser considerada somente um fazer técnico ou instrumental dos profissionais da educação, possuindo sentidos e significações que podem ser compreendidos por outras pessoas distintas dos professores, baseando-se em seus ajustamentos na história, na tradição e na ideologia.

Sobre os sentidos e significações da prática, Kemmis assinala quatro planos de grande significação. $O$ primeiro se refere às "intenções do profissional". Ou seja, sua posição diante da classe, sua atenção ao desenvolvimento das discussões e propostas, para que, a partir do conhecimento do tema, seja facilitada a compreensão e apropriação do mesmo pelos alunos. O segundo, o plano social, é interpretado não somente pelos agentes da educação, mas também pelos demais envolvidos neste processo de aprendizagem - os estudantes. O terceiro plano é a relação histórica do agente com o aluno, com os demais estudantes da classe e com as pessoas da escola. O quarto plano está baseado na construção política da classe, onde se cria uma micropolítica que poderá apresentar duas faces distintas. Ou seja, poderá ter uma configuração baseada na dominação e submissão ou na democracia, com discursos e processos abertos e progressistas.

Prosseguindo nesta direção, Kemmis (apud Carr, 1996, p. 24) acrescenta:

E, além desta micropolítica, a prática da classe também está configurada por fatores sociais, materiais e históricos que transcendem ao controle de nós que estamos em aula - por meio das relações de classe social, das relações de gênero, fatores lingüísticos, culturais etc.

As reformas dos sistemas educativos teriam que implicar discussões, não somente entre especialistas e docentes, mas também entre todos aqueles que participam da sociedade e nesta podem fazer suas intervenções. Somente com uma ampla participação social esse problema cultural encontrará alternativas que contemplam a realidade. Assim, concordando com Sacristán (1998, p. 23) também acreditamos que a prática da educação é uma prática social. 


\section{O CURRICULUM E A PRÁTICA PEDAGÓGICA}

\section{Os distintos conceitos do curriculum}

Sendo uma linguagem recente na teoria da educação, o conceito de curriculum no dicionário brasileiro tem uma definição muito limitada e está relacionada exclusivamente à etimologia da palavra, ou seja: "currículo - as matérias constantes de um curso" (Ferreira, 1975, p. 412).

Não obstante seus avanços em relação à teoria da educação no Brasil, o curriculum foi por muitos anos considerado uma área meramente técnica, cuja valorização estava baseada nos procedimentos, técnicas e métodos utilizados na escola (Moreira, 1995, p. 7). Sob este ponto de vista tradicional, é evidente a definição de currículo que nos chega dos Estados Unidos através de Kliebard, baseada na racionalização:

o curriculum tem sido definido como uma teorização ahistórica, que o leva em muitas ocasiões a difundir modelos descontextualizados no tempo e com respeito às idéias que fundamentam, sob a preocupação utilitarista de buscar as "boas" práticas e os "bons" professores para obter "bons resultados educativos". (apud Sacristán, 1995, p. 43).

As teorias do curriculum costumam ressaltar concepções políticas e técnicas que, historicamente, têm sido ordenadas para administrá-lo, expressando fórmulas para sua elaboração e desenvolvimento. Segundo Sacristán (1995), estas teorias desempenham funções fundamentais para a seleção de temas e perspectivas, e dos formatos a serem consumidos pelos professores; ressaltam certas funções dos profissionais da educação e dão racionalidade às práticas escolares. Portanto,"as teorias curriculares se convertem em mediadoras ou em expressões da mediação entre o pensamento e a ação em educação". (Sacristán, 1995, p. 44).

Isto tem ocorrido porque professores e alunos são os destinatários do curriculum, e os professores são os primeiros agentes transformadores do projeto cultural. Ainda que os discursos necessitem 
de maturidade, há inúmeros autores que se aproximam da sistematização de opções ou de orientações teóricas curriculares.

Atualmente já se reconhece uma tradição crítica do curriculum que tem como guia questões sociológicas, políticas e epistemológicas. Assim, o curriculum é considerado como instrumento social e cultural em uma significação mais ampla, a das suas determinações sociais, históricas e de produção contextual. Portanto, ele não é neutro, nem tampouco está desinteressado na transmissão do conhecimento social. Sem dúvida, o curriculum tem implicações com a ideologia da cultura, com o poder e com as distintas visões de mundo a serem transmitidas às diferentes classes sociais (dominantes e dominados).

Continuando esse direcionamento, baseado em Althusser, Moreira (1995, p. 21) considera que o curriculum e a escola transmitem as idéias sobre o mundo social, garantindo a reprodução da estrutura social existente. Sem dúvida, o autor vai além dos pressupostos de Althusser, conceituando ideologia com maior profundidade. Fugindo a questionamentos do tipo "ideologia como conhecimento falso e não-ideologia como conhecimento verdadeiro", ele afirma:

A ideologia, nessa perspectiva, está relacionada às divisões que organizam a sociedade e às relações de poder que sustentam essas divisões. O que caracteriza a ideologia não é a falsidade ou a verdade das idéias que veicula, mas o fato de que essas idéias são interessadas, transmitem uma visão do mundo social vinculada aos interesses dos grupos situados em uma posição de vantagem na organização social (Moreira, 1995, p. 23).

Portanto, a pergunta que devemos formular é: "a quem esta ideologia beneficia?" Ela nos aproximará do conceito de ideologia e de suas relações de poder. Significará um questionamento da noção de conhecimento como representação da realidade implícita na perspectiva pistemológica da ideologia. A ideologia nos chega de maneira sutil e de forma tão refinada que muitas vezes não a percebemos, pois vai se aproveitando dos materiais existentes na cultura e na sociedade, que pertencem ao senso comum. Em primeiro lugar, não possui uniformidade, homogeneidade, nem coerência de 
idéias, pois ela é feita por fragmentos dos distintos conhecimentos. Sua outra dimensão está relacionada com mecanismos de transmissão, pois utiliza os livros de textos e as aulas dos professores para materializar-se nos rituais, nas práticas, signos, linguagens etc. Sem dúvida, a ideologia não é idealista e atua no conhecimento para produzir identidades individuais e sociais, através do curriculum escolar.

Curriculum cultura é outra dimensão analisada por Moreira (1995, p. 22), em que são assinaladas duas visões diferentes. Uma visão da cultura na "teoria tradicional", definida e limitada como um conjunto inerte e estático de valores e conhecimentos, e o curriculum como uma forma institucionalizada de transmiti-la. Já na "tradição crítica", a cultura é considerada em uma política cultural, ativa e integrada nos processos de produção e criação de sentidos, significações e sujeitos. Portanto, o curriculum é um terreno de produção e de criação simbólica, onde os conflitos da vida social se manifestam.

Sobre o curriculum poder, a terceira dimensão, o autor fala, inicialmente, da influência do poder nas relações sociais e da influência que a elite dominante exerce sobre os indivíduos e grupos sociais. Faz também os seguintes questionamentos: Quais são as forças que fazem o curriculum oficial hegemônico? Quais prolongam as relações de poder? E afirma que estas forças se encontram tanto nos grupos e classes dominantes corporificados no Estado (Moreira, 1995, p. 25-30) como nos inúmeros rituais da cotidianidade escolar.

Daí concluirmos que, não sendo possível a extinção total do poder, nos restará a luta constante para a transformação do mesmo em um curriculum onde nosso compromisso deverá estar nos distintos campos: no cultural e no da construção e produção de significações e sentidos.

\section{As práticas: saberes compartidos}

Teorizar sobre a educação foi algo considerado fora da prática pela maioria dos professores. Ou seja, a teoria acontece em lugares e tempos diferentes da prática, em lugares cheios de paz e 
tranquiilidade, envolta por livros, folhas de papel etc. Já a prática desenvolveu-se na cotidianidade das aulas na escola, nos rituais pedagógicos numa interação direta com os alunos. Assim, para Kemmis (apud Carr, 1996, p. 23), a teoria possui dois sentidos: o retrospectivo, que permite a interpretação dos quebra-cabeças práticos, e o prospectivo, que "oferece orientação e talvez induza normas para a prática". Portanto, esta é uma relação de pensamento e de ação com uma concepção estreita, individualista e racionalista, não permitindo uma análise mais aprofundada das relações e estruturas sociais. Isto resultaria em um modo de se ocupar destas relações como um processo público, começando por uma reflexão em que não há separação entre teoria e prática.

No senso comum, teoria e prática não só estão separadas por lugares e tempo como também pela divisão do trabalho e pela diferenciação das funções nas estruturas institucionais. Portanto, é necessário aclarar-se que este distanciamento deve ser explicado, interpretado e justificado por uma teoria independente da teoria da educação e do ensino. Sem dúvida, há relações entre elas, mas não estão claras "que práticas se submetem à teorização, quando e a cargo de quem?" (Carr, 1996, p. 34).

Deste ponto de vista, poderemos descobrir que a teoria e a prática não se separam. As práticas cobram significados quando são teorizadas, e as teorias adquirem significação histórica, social e material quando praticadas. Portanto, a teoria e a prática são mutuamente constitutivas através das atividades humanas, sociais e, também, dos "processos públicos (práticas) de reflexão e auto-reflexão críticas" (Carr, 1996, p. 34).

A importância deste sentido mais amplo demonstra que o saber teórico está mediado pelas mentes dos indivíduos, pelas atividades sociais consideradas como processos públicos entre grupos de pessoas ou comunidades inteiras. Ainda segundo MacIntyre (apud Carr, 1996, p. 35):

(...)as práticas são julgadas de acordo com critérios e tradições publicamente compartidos; com as vidas, virtudes e excelências dos práticos, enquanto portadores dessas tradições e em relação com o trabalho de instituições criadas para alimentar e sustentar estas atividades e valores, virtudes e excelências que levam consigo e os expressam. 


\section{EDUCAÇÃO FÍSICA E CURRICULUM}

\section{Uma reflexão sobre os valores e os fins da Educação Física Escolar}

Quando iniciamos um estudo do curriculum com uma visão da Educação Física (EF), aparecem algumas dificuldades que têm origem em sua história e evolução enquanto uma disciplina do curriculum escolar.

Os estudos referentes à história social da EF são escassos e só recentemente alguns trabalhos têm-se aprofundado nesta questão. Apesar de a EF estar sempre presente no curriculum escolar, ela não é "uma disciplina estável e invariável". Sua evolução ocorreu de maneira "linear à da ginástica do século XIX e ao desporto do século XX” ( Devís, 1996, p. 13).

Devís considera de grande importância os trabalhos realizados pelos britânicos Hargreaves (1986) e Kirk (1992) e pelo francês During (1992), que marcaram a evolução social e cultural da EF no curriculum escolar. Sem dúvida, esta área do curriculum não tem tido a devida valorização quanto ao seu significado sociocultural.

No estudo de Goodson (apud Kirk) são apontados alguns aspectos históricos que caracterizam as matérias de geografia, história e outras do curriculum escolar, na tentativa de explicar as mudanças sofridas por elas. $\mathrm{O}$ autor desenvolveu três hipóteses, que Kirk aproveita para uma análise da Educação Física:

1. As disciplinas não são entidades monolíticas, senão amálgamas cambiantes de subgrupos e tradições. Estes grupos dentro da disciplina influem e mudam as fronteiras e prioridades.

2. No processo de estabelecimento da base de uma disciplina escolar (e de uma disciplina universitária associada), os grupos da matéria tendem a transladar-se da promoção de tradições pedagógicas e utilitárias para as tradições acadêmicas.

3. Nos casos estudados, a maior parte do debate do curriculum pode ser interpretado em termos de conflito entre disciplinas com respeito ao status, aos recursos e ao território (Kirk, 1990, p. 102).

Na história universal da EF, o primeiro enunciado demonstra que ela não é um corpo fixo de conhecimentos, mas sim que ao 
longo dos anos sofreu distintas mudanças por influência dos grupos de profissionais que lutaram para defender suas próprias visões da disciplina, comparando as finalidades, as vantagens e desvantagens entre as diferentes escolas de ginástica, principalmente de países como Suécia, Alemanha e França. De acordo com cada um destes grupos, os conteúdos e enfoques do conhecimento são variáveis. Portanto, até hoje fica difícil uma definição clara do conteúdo da EF e suas finalidades, uma vez que ela incorpora conteúdos de outras áreas.

No Brasil, esta evolução também não foi diferente, pois sofreu as influências destas escolas européias, dos pensamentos positivista e militarista. Somente nos anos 80 a produção acadêmica começou a construir uma nova visão da Educação Física Escolar. Sobre isto nos aprofundaremos mais adiante.

No segundo enunciado são evidenciadas as transformações sofridas pelas disciplinas, e, aqui, pela $\mathrm{EF}$, que a princípio tratava dos conhecimentos utilitários da prática física e, depois, buscava justificações para a matéria, com base no conhecimento científico. Assim, pretendia-se que

as ciências servissem de ajuda e apoio ao processo de racionalização das atividades profissionais e sobretudo servissem para elevar o status da profissão podendo introduzir e assentar a Educação Física como disciplina do curriculum escolar (Kirk, 1990, p. 15).

O corpo de conhecimentos da medicina foi o principal eixo que justificou e ofereceu sustentação e status à EF no curriculum escolar. Outras ciências sociais também influenciaram em sua evolução, tais como a pedagogia científica e a psicologia experimental.

Os conflitos e debates entre as disciplinas do curriculum, ou entre a EF e as outras disciplinas, estão marcados pela dicotomia teoria-prática, o que significa a valorização das disciplinas ditas "acadêmicas" em detrimento das outras de caráter "prático", como é o caso da Educação Física.

Intencionalmente, a EF foi considerada uma disciplina sem valor acadêmico ou educativo, sendo sempre associada às atividades físicas e lúdicas; portanto, não é "séria", nem "produtiva". Sob esta 
visão de baixo "status educativo" e do caráter "antiacadêmico" que se lhe atribui, a Educação Física, ainda que logre de tradição no curriculum escolar, está em um baixo nível hierárquico em comparação com as outras disciplinas escolares. Várias pesquisas já o comprovaram, como, por exemplo, a de Gutierrez (1996), citada por Devís, concluindo que tal fato deve ser causado pela incorporação de novos profissionais de outras áreas, ou pela desatualização profissional. Também Apple e King fazem um estudo com meninos e meninas do pré-escolar e constatam que as disciplinas ditas "acadêmicas" são consideradas "sérias e produtivas", enquanto o jogo e as atividades de Educação Física são "divertidas, triviais, supérfluas, e que os alunos e alunas vão à escola para trabalhar e não para brincar" (Devís, 1996, p. 17).

Sem dúvida, o status da EF como uma atividade educativa no curriculum escolar é problemático e nós, como profissionais, teremos muito de lutar por isto. Segundo Kirk (1990), ao teorizar sobre as mudanças do curriculum de EF, é necessário relacionar o status desta com as demais, dentro do curriculum geral.

Comumente, o conteúdo da EF é amplamente reconhecido como movimento ou atividade física, e muitos autores a consideram responsável pelo desenvolvimento da "competência motriz e da condição física". Mas não há coerência quanto aos tipos de atividades que devem compor o curriculum desta disciplina.

Kirk (1990, p. 81) assinala que isto dependerá de uma série de fatores, ou seja:

os propósitos da gente que apóia a Educação Física no curriculum, a relação destes propósitos com as condições do aluno (idade, tempo e nível), a posição social dos alunos e a natureza da escolaridade que eles tenham experimentado.

Este autor exemplifica, também, a distinção feita na Inglaterra em meados do século XIX, quando os alunos das escolas públicas pertencentes às classes governantes teriam os jogos desportivos extracurriculares obrigatórios. E o conteúdo de Educação Física dos alunos das classes baixas era composto de "exercícios sistematizados e disciplinados". Além disso, seu conteúdo estava adaptado às ocasiões desportivas da escola, e a seleção das atividades costuma- 
va ser aquelas práticas de acordo com as estações do ano. As categorias de atividades se convertiam no conteúdo prático do curriculum, como enumera Kirk (1990, p. 81):

- Ginástica

- Atletismo

- Atividades aquáticas (natação, vela, remo, atividades de sobrevivência)

- Jogos desportivos e desportos (equipe e individuais)

- Dança (tradicional, expressiva/criativa, moderna, social, ballet)

- Atividades ao ar livre (acampamentos, canoagem, escalada, esqui)

Assim, o espaço conquistado pela EF, no curriculum geral, tem uma significação de avanço, mas se transformou em mais um dos elementos laicos que a constituíram. Isto tem representado um atraso, significando o disciplinamento e a limitação dos movimentos e tornando-se um instrumento a mais nas mãos da burguesia, que fazia veicular seu modelo de corpo, de atividade física e de saúde, e sua ideologia (Soares, 1994).

Segundo Soares, a EF do século XIX foi inspirada nos modelos do liberalismo e do positivismo, deles absorvendo as regras para os desportos modernos (surgidos na Inglaterra), com aparência de "universais", nos quais todos teriam oportunidades de ganhar o jogo e vencer na vida através de seu esforço próprio. Do positivismo, absorveu a concepção do homem biológico e orgânico, determinado geneticamente e necessitado de adestramento e disciplina.

A EF estava, assim, direcionada para a formação de um "homem saudável, disciplinado e trabalhador", pois o contexto industrial assim exigia. $\mathrm{O}$ exercício físico teria de resolver os problemas da sociedade industrial e de ser capaz de neutralizar os conflitos sociais, equilibrando a vida do trabalho.

A saúde do homem só era importante porque ele, neste contexto, se transformara em um acessório da máquina e deveria ser capaz de suportar as longas horas de trabalho em posições nocivas ao seu corpo. 
Mesmo que, na atualidade, os professores tenham adotado metas diferentes, como "fomentar estilos de vida saudáveis e promover a ocupação do tempo de ócio" (Kirk, 1990, p. 58), os conteúdos da Educação Física continuam pouco educativos.

A Educação Física é obrigatória nas escolas, mas é periférica; muitos professores, alunos e pais a consideram sem valor educativo em comparação às demais disciplinas do curriculum escolar.

De acordo com as visões da Educação Física aqui apresentadas, seus fins e valores estão baseados no senso comum, em uma visão ortodoxa e estreita. Neste sentido, concordamos com Kirk (1990, p. 590), quando afirma que "se nós professores não estamos dispostos e não somos capazes de dar um valor educativo à nossa disciplina, estaremos restringindo nosso potencial de contribuição para um processo educativo emancipatório".

\section{Práticas educativas críticas no ensino da Educação Física Escolar}

Com o aparecimento da Escola de Frankfurt na Alemanha, a teoria crítica teve sua fundamentação nos anos 20 e 30. Preocupados com a primazia das ciências naturais em todas as áreas da vida acadêmica, social e política, Max Horkheimer, Theodor Adorno e Herbert Marcuse observaram a "erosão da razão" e o surgimento do fascismo. Isto foi debilitando a sociedade democrática, a sensatez e a civilização em geral (Kirk, 1990, p. 34).

A tecnificação, fortemente ampliada na vida cotidiana, tornara-se uma característica marcante do mundo capitalista para manter a produtividade industrial. Aqueles autores "sugeriram que a forma de combater este processo seria através da crítica de muitas assunções e crenças que se dão por supostas e que reforçam o processo de tecnificação" (Kirk, 1990, p. 34).

Somente 50 anos mais tarde a teoria crítica começou a influenciar alguns especialistas da educação, isto porque a tecnificação tinha reflexos no ensino e na aprendizagem nas escolas. A resposta destes especialistas contribuiu para a modificação dos cursos de formação do professorado, através de uma "investigação orientada", tentando, assim, um combate a este processo de tecnificação. 
A "pedagogia crítica" de Giroux também tornou-se um meio para a auto-reflexão crítica dos alunos e professores. E, segundo Kirk (1990, p. 35),

através deste processo tenta-se que as pessoas cheguem a ser conscientemente críticas das forças que estão subjacentes e que apóiam as práticas opressoras e injustas da sociedade e, deste modo, se encontrem em melhor disposição para enfrentá-las e transformá-las.

Portanto, o papel da educação é oferecer instrumentos de poder através do conhecimento, da compreensão e da consciência crítica. Sem dúvida, isto não significa que a emancipação e as mudanças sociais ocorram automaticamente; é necessário que os educadores, junto aos grupos politicamente ativos na sociedade, coordenem estas ações (Gibson, apud Kirk, 1990).

Os estudos de Kirk fazem uma importante aproximação desta visão "do curriculum como práxis educativa" com a "prática da educação física nas escolas"; nela as críticas estão direcionadas "às intenções, crenças e suposições que estão subjacentes nestas práticas". Ele defende, ainda, que o estudo da Educação Física e do curriculum é necessário para a mudança e emancipação da sociedade, sendo que a escola e a educação têm um papel fundamental nisto. Convoca os professores, como protagonistas neste processo, a lutar pelas transformações através do estabelecimento de uma "pedagogia crítica na Educação Física". E, a partir deste ponto, faz pesquisas com o objetivo de "localizar esta visão dos professores, as escolas e a mudança social emancipatória no contexto das tendências e acontecimentos recentes no campo do curriculum "( Kirk, 1990, p. 35).

No Brasil, os estudos sobre a teoria educacional crítica não foram divulgados suficientemente, todavia existem trabalhos muito importantes desenvolvidos por Moreira e Silva (1994). Estes autores tentam responder à ausência do diálogo entre a pedagogia brasileira, a sociologia e a teoria crítica do curriculum.

A pedagogia da Educação Física brasileira encontra-se em um processo de construção e de consolidação, em suas vertentes críticas. Há vários estudiosos buscando novos elementos teóricos e 
metodológicos para os futuros desenvolvimentos desta área (Ferreira, 1995).

Entendemos a perspectiva crítica como aquela em que a análise e a teoria têm em vista um projeto cultural de transformação do mundo existente; portanto, quanto mais ampliarmos nossa compreensão do mundo e da dinâmica social, mais fortaleceremos uma tradição politicamente comprometida (Ferreira, 1998).

Em sua evolução histórica a EF brasileira tem vivido momentos paradoxais. De uma parte, pertence oficialmente à instituição educacional; as orientações no interior da escola são originárias das instituições militar e esportiva. Isto prejudicou seu desenvolvimento e a construção de um corpo próprio de conhecimentos, facultando àquelas instituições sua utilização como meio do fortalecimento dos interesses sociais das classes hegemônicas. E assim cumpria as funções sociais e pedagógicas típicas das instituições militar e esportiva, que determinavam seus conteúdos, objetivos e avaliação, principalmente nas décadas de 1930, 1940 e 1950.

A EF, no Brasil dos anos 60, teve uma influência da medicina higienista, objetivando a conservação da saúde e da moral através dos exercícios físicos. Portanto, "a higiene do corpo e da alma eram inseparáveis" (Moura, 1995, p. 37). Sem dúvida, esta concepção da EF preconizava atividades advindas do exterior, como a ginástica, que não só era um agente de saúde, mas também exercia uma forte influência moralizadora, intelectual e física nos alunos.

Os elementos da pedagogia foram incorporados pela EF em uma versão tecnicista, através da didática, e, apesar da pedagogização, os pensamentos higienistas e militares criaram uma idéia falsa sobre a neutralidade das práticas corporais. Então, aos professores só interessava a técnica. Esta postura tecnicista era decorrente da censura e da repressão impostas à sociedade brasileira pelo Golpe Militar de 1964.

Somente a partir dos anos 80 a sociedade brasileira começava a conquistar espaços e a elaborar novas estratégias para a superação deste momento intervencionista. O pensamento crítico da EF acompanhou este processo e vários autores apontaram para um movimento de renovação teórica da EF brasileira (Oliveira, 1994). Portanto, para que ela pudesse compartilhar de uma nova ordem 
econômico-social, era necessário despojá-la das heranças higienistas e militares para construir uma teoria crítica da EF. Assim, várias pesquisas relevantes surgiram. Entre elas ressaltamos as de Costa (1999), Bracht (1986), Castellani Filho (1988), Coletivo de autores (1992) e outros - todas elas oferecendo subsídios à EF brasileira, que, ao transformar-se, dá um salto qualitativo, não só em relação à sua prática, mas também em relação aos pressupostos teóricos, dialeticamente produzidos e responsáveis pela superação dessa prática.

Em recente trabalho de investigação, Ferreira (1998) apresenta um estudo sobre a produção teórica da EF brasileira e faz comparações, confrontos e discussões entre as distintas teorias, visando construir novos quadros teóricos de referência. Todavia, não se afasta da prática, mantendo um compromisso com os professores e professoras na escola. Sem dúvida, o pensamento positivista na EF ainda constitui um grande obstáculo à sua inovação filosófica.

\section{CONCLUSÃO}

A maioria conservadora dos(as) professores(as) de EF no Brasil acusa os adeptos da nova pedagogia de somente apresentarem críticas e denúncias. No entanto, um dos maiores obstáculos para esta transformação está na resistência às mudanças, no medo ao desconhecido. É preciso transgredir, ousar. Ao nos acomodarmos na igualdade, fortalecemos as desigualdades e simplificamos nosso trabalho docente na administração da sala de aula e na manutenção da ordem.

A diversidade é peculiar a cada um de nós e depende de nossa "organização intrínseca, das interações ambientais, das experiências vividas e no âmbito da cultura está marcada pela memória coletiva" (Costa, 1999, p. 528).

Portanto,

Para assumir as diferenças é necessário partir da diversificação de conteúdos e formas de adquirir aprendizagens. Respeitar o ritmo, as possibilidades de cada aluno/a em cada momento, não é tarefa fácil. Devemos assumir as aulas estando dispostos a tratar com o imprevisível. Não devemos limitar as aulas às situações repressivas e 
homogeneizadoras. As experiências e as relações com as alunas/os nos permitem sair fora do círculo vicioso e enfrentar os aspectos negativos. (Costa, 1999, p. 528)

As diferentes tendências críticas socialistas, como a "crítica superadora", a "Educação Física necessária", a "crítica emancipadora" e outras desenvolvidas no Brasil, têm demonstrado as possibilidades de mudanças e contribuído para o debate e a reflexão. No entanto, sente-se a necessidade de um diálogo mais aberto entre elas, o que possibilitaria um enriquecimento na construção de um curriculum que valorizasse um processo permanente e produtivo na reconstrução do conhecimento. Um curriculum fundamentado na investigação, tanto de professores(as) como de alunos(as); que valorizasse a visão multilateral para a sistematização do ensino da $\mathrm{EF}$; que valorizasse a cultura corporal e suas múltiplas manifestações, respeitando as diferenças étnicas, de gênero, de classe etc.

As várias experiências alternativas já realizadas no Brasil, como aquelas desenvolvidas no MST (Rio Grande do Sul) e na Escola Plural (MG), têm demonstrado as grandes possibilidades de mudança, necessitando, apenas, de maior ênfase na teorização e difusão. Isto tem demonstrado que é possível desenvolver uma $\mathrm{EF}$ crítica, de intervenção social e que contribua para a formação de um cidadão crítico e reflexivo.

\section{ABSTRACT}

This study presents different conceptions of educational practice and its historical evolution by searching, among several authors, elements to clarify the gap between Theory and Practice and its socio-cultural effects. It is also aimed at relating the educational practice, the theory and the curriculum with the values and finalities of Physical Education programs at Schools.

KEYWORDS: Theory - Educational Practice - Curriculum - Ideology - Physical Education.

\section{REFERÊNCIAS}

BRACHT, V. A criança que pratica esporte respeita as regras do jogo... capitalista. Revista Brasileira de Ciências do Esporte, v. 2, p. $62-68,1986$. 
CARR, W. Una teoría para la educación: hacia una investigación educativa crítica. Madrid: Ed. Morata, 1996.

CASTELANI FILHO, L. Educação Física no Brasil: a história que não se conta. Campinas: Papirus, 1988.

COLETIVO DE AUTORES. Metodologia do ensino da Educação Física. São Paulo: Cortez, 1992.

COSTA, M. R. F. O lugar da diferença na formação em Educação Física: um estudo de caso institucional no departamento de EF da Universidade Federal do Paraná - Brasil. 1999. Tese (Doutorado) Universidade de Barcelona.

DEVÍS, J. Educación fisica, deporte y curriculum: investigación y desarrollo curricular. Madrid: Visor, 1996.

FERREIRA, A. B. H. Novo dicionário da língua portuguesa. Rio de Janeiro: Nova Fronteira, 1975.

FERREIRA, M.G. Teoria da Educação Física: bases epistemológicas e propostas pedagógicas. In: FERREIRA NETO A.; GOELINER, S. V \& BRACHT, V. (Orgs.). As ciências do esporte no Brasil. Campinas: Autores Associados, 1995.

Sociologia do Currículo: contribuições para o desenvolvimento de uma perspectiva crítica na pedagogia da educação física. 1998. Dissertação (Mestrado) - Universidade Federal de Santa Maria, Santa Maria.

KIRK, D. Educación física y curriculum. Valencia: Universitat de Valencia, 1990.

MOREIRA, A. F. (Orgs.). Currículo, cultura e sociedade. São Paulo: Cortez, 1995.

MOREIRA, A. F. B.; SILVA, T. T. (Orgs.). Currículo, cultura e sociedade. 2. ed. São Paulo: Cortez, 1995.

MOURA, S. A. A relação professor - aluno: alegrias e rupturas na Educação Física Escolar. 1995. Monografia. Faculdade Educação Física, Universidade Federal de Goiás. 
OLIVEIRA, V. M. Educação física humanista. Rio de Janeiro: Ao Livro Técnico, 1985.

OLIVEIRA, V. M. Consenso e conflito da Educação Física brasileira. Campinas: Papirus, 1994.

SACRISTÁN, J. G. El curriculum: una reflexión sobre la práctica. Madrid: Ed. Morata, 1995.

Poderes insetables en educación. Madrid: Ed. Morata, 1998.

SOARES, C. L. O pensamento médico-higienista e a Educação Física no Brasil: 1850/1930. 1990. Dissertação (Mestrado) Pontifícia Universidade Católica de São Paulo.

TAFFAREL, C. N. Z. Criatividade nas aulas de Educação Física. Rio de Janeiro: Ao Livro Técnico, 1985. 